\title{
FINE STRUCTURE OF THE OVIDUCT OF THE LAYING HEN
}

\author{
G.-M. WYBURN, H.-S. JOHNSTON and M.-H. DRAPER \\ Anatomy Department, The University, Glasgow W2 (Great Britain) \\ Poultry Research Centre, King's Buildnigs, West Mains Road, \\ Edinburgh 9 (Great-Britain)
}

The classic work on the Histology of the hen's oviduct is that of Richardson (I935). The electron microscopic observations recorded here, broadly confirm his histological survey but paradoxically the more intimate knowledge of intracellular structure emphasizes rather than simplifies the quite unique problem of the performance of $68 \mathrm{~cm}$ of oviduct, which, in the laying hen, provides every 24 hours, the substance for the coverings of the egg.

The material was obtained from eight laying birds, one with no egg in the oviduct; four with an egg in the magnum; one with an egg in the isthmus; and two with an egg in the shell gland. The hens were perfused with I p. Ioo Gluteraldehyde before obtaining samples of the mucous membrane from the different regions of the duct for preparation.

The pattern of folds of the mucous membrane varies throughout the duct. The innermost epithelial lining has two cell types, - ciliated and glandular, with a characteristic arrangement in the different regions. The cells of the tubular glands of the infundibulum, magnum, isthmus and shell gland have common and distinctive features.

\section{THE INFUNDIBULUM}

The longitudinal folds of the mucous membrane, increase in size towards the magnum.

The covering epithelium of the surface of the folds has a regular alternation of ciliated cells with apically situated nuclei and glandular cells with basal nuclei and collections of electron dense granules at the apex which bulge into the lumen In the crypts or granular grooves between the folds, there are no ciliated, but only granular cells with a strikingly constant arrangement of apical granules, the nucleus surmounting a basaly situated dilated cisterna of endoplasmic reticulum. The glands of the infundibulum are in effect, tubular evaginations of the glandular grooves, 
which in transverse section, appear as an acinar arrangement of cells round a small lumen, with apical granules and characteristic dilated basal cisternae of endoplasmic reticulum. A thick, jelly-like mucin is deposited on the ovum as it passes through the posterior portion of the infundibulum. This, together possibly with some secretion from the anterior part of the magnum, constitute the substance of the chalazae and the chalaziferous layer.

\section{THE MAGNUM}

The mucous membrane of the magnum has larger and broader folds and a thicker glandular layer than elsewhere in the oviduct.

The epithelium of the upper magnum, shows the regular alternation of ciliated and glandular cells with apices packed with pale, translucent granules budding hinto the lumen. Towards the lower magnum, the epithelium increases in height, and the glandular cells are distended with large pale granules, compressing the ciliated cells into narrow strips of cytoplasm with nuclei and expanded ciliated apices. There was no evidence that the ciliated and glandular cells represented different phases of a common epithelial cell.

The cells of the tubular glands are filled with granules, varying from small to very large. In some of the cells, they are massed so closely together that the cell outlines are obscure. Elsewhere, the cytoplasm between the granules is filled with cisternae of endoplasmic reticulum and Golgi apparatus, with a small basaly situated nucleus. The lumen of the magnum is filled with electron dense secretion. When there is an egg in the magnum, some of the glands immediately above the egg are almost empty of granules. These cells are now wholly occupied with dilated cisternae of endoplasmic reticulum filled with a homogenious secretion and there is prominant Golgi apparatus containing both large and small granules. These represent regenerating cells. It is improbable that all the glands of the magnum adjacent to the egg, shed their granules. It fact, the lumen of the duct below the egg is filled with secretion. With the rapid turnover in the laying hen, it would seem probable that at any one time, there is likely to be throughout the magnum, glandular cells in all phases of secretory activity. The openings of the glands are lined with secretory cells right up to the surface.

\section{THE ISTHMUS}

Folds of the mucous membrane of the isthmus are not as high as those in the magnum, tend to be less spiral and more regularly disposed in the long axis of the duct. There is quite an abrupt change in the electron microscopic appearance of the epithelium from the distended goblet-like cells and compressed ciliated cells of the lower magnum, to a regular alternation of glandular and ciliated cells of approximately similar width. The glandular cells have aggregations of electron dense granules, particularly in the apical part of the cell, and the apices packed with those granules, protrude into the lumen. In this region there are also a few electron dense 
granules in the ciliated cells. There appear to be fewer granules and less protrusion of the glandular cells when the egg has passed into the shell gland. In what corresponds to the anatomical isthmus, there are two quite distinct types of cell forming the tubular glands. At the magnum end, the cells are packed with electron dense granules, and resemble the glands of the magnum, the only distinctive feature being some endoplasmic reticulum filled with an electron dense material, and on average fewer of the large sized granules. At the lower end, the cells resemble those of the shell gland. There are no, or few dense granules, but conspicuous collections, of mitochondria with characteristic dense cristae. Throughout the cell, there are small particles corresponding in size to those of glycogen granules, arranged discretely or in clusters, sometimes contained in large vacuoles. There are duplications and infoldings of the cell membrane and the microvillae of the cell apex fill the lumen.

\section{THE, SHELI, GLAND}

The epithelium of the shell gland resembles very closely that of the lower isthmus with perhaps less protrusion of the apices of the glandular cells. The cells of the glands of this portion of the oviduct also resemble those of the lower isthmus. Again the mitochondria are a prominent feature and characteristically, there are bizarre forms of granules with all degrees of density. A feature of these cells is an unusual complexity of the microvillae, some of which are elongated with bulbous tips which bud off and appear to form part of the cell secretion. The small glycogen-like particles, although still present, are not so conspicuous as those in the cells of the lower isthmus.

What emerges from this study, is that there are four basic cell types which provide all the constituents, organic and inorganic of the egg coverings. The ciliated and glandular cells of the epithelium and the protein and ion type of cell of the tubular glands. These results would seem to caution against a too rigid acceptance of the oviduct as an assembly belt contributing the coverings of the egg in an orderly sequence in time and place as distinct and completed items. It is known for example, that the chalazae are formed by mechanical action on secretions obtained from both the infundibulum and the anterior magnum, and that the egg has only half its quantity of white when it reaches the shell gland where there is an interchange of protein and fluid between the different layers of albumen. Again, while the glands of the lower isthmus and shell gland have characteristic ion-secreting cells, there is evidence of ion exchange at all levels of the oviduct.

\section{REFERENCE}

RichaRdson K. C., I935. The secretory phenomena in the oviduct of the fowl including the process of shell formation examined by the microincineration technique. Phil. Trans. R. Soc. London B., 225, I 49-I 95 . 